\title{
ALGUNS ELEMENTOS DA HISTÓRIA DA EDUCAÇÃO MATEMÁTICA NO ESTADO DE SANTA CATARINA, BRASIL, NO SÉCULO 20: A ARITMÉTICA NOS GRUPOS ESCOLARES
}

\author{
David Antonio da Costa \\ Universidade Federal de Santa Catarina, Brasil.
}

\begin{abstract}
Resumo
O modelo dos grupos escolares difundiu-se, gradativamente, pelos demais Estados brasileiros a partir de São Paulo, no início do século 20. Este texto analisa, historicamente, a trajetória da constituição dos saberes elementares, particularmente a Aritmética, no Estado de Santa Catarina e toma como documento de pesquisa os textos escolares normativos. As características presentes nos textos sobre o ensino de Aritmética revelam vestígios da influência paulista nos materiais didáticos e na metodologia de ensino da Aritmética prescritos para uso em Santa Catarina.

Palavras-chave: aritmética, grupo escolar, legislação.

\section{SOME ELEMENTS OF THE HISTORY OF MATHEMATICS EDUCATION IN THE STATE OF SANTA CATARINA, BRAZIL, IN THE EARLY TWENTIETH CENTURY: THE ARITHMETIC IN SCHOOL GROUPS}

Abstract

The model of school groups spreads gradually for the other Brazilian states from Sao Paulo in the early twentieth century. This text analyzes the historical trajectory of constitution of the elementary knowledge; particularly the Arithmetic in the State of Santa Catarina and it takes as a research resource the school legislative texts. The characteristics present in the texts on teaching Arithmetic reveal traces of influence in São Paulo didactical materials and teaching methodology of prescribed arithmetic for use in Santa Catarina.

Key-words: arithmetic, school group, legislation.

\section{ALGUNOS ELEMENTOS DE LA HISTORIA DE LA EDUCACIÓN MATEMÁTICA EN EL ESTADO DE SANTA CATARINA, BRASIL, EN PRINCIPIOS DEL SIGLO 20: \\ LA ARITMÉTICA EN LOS GRUPOS ESCOLARES}

\section{Resumen}

El modelo de los grupos escolares se difunde gradualmente por los demás Estados brasileños a partir de São Paulo en el inicio del siglo 20. Este texto analiza históricamente la trayectoria de la 
constitución de los saberes elementales, particularmente la Aritmética, en el Estado de Santa Catarina y toma como fuente de investigación los textos escolares normativos. Las características presentes en los textos sobre la enseñanza de Aritmética revelan vestigios de la influencia paulista en los materiales didácticos y en la metodología de enseñanza de la aritmética prescritos para uso en Santa Catarina.

Palabras-clave: aritmética, grupo escolar, legislación.

\section{QUELQUES ÉLÉMENTS DE L'HISTORIE DE L' ENSEIGNEMENT DES MATHÉMATIQUES DANS L'ÉTAT DE SANTA CATARINA, BRÉSIL, AU DÉBUT DU 20e SIĖCLE: L'ARITHMÉTIQUE DANS LES GROUPES SCOLAIRES}

\section{Résumé}

Le modèle de groupes scolaires s'étend progressivement à d'autres États de Sao Paulo au début $\mathrm{du} 20 \mathrm{e}$ siècle. Ce texte analyse historiquement la trajectoire de la constitution des savoirs élémentaires notamment l'Arithmétique dans l'État de Santa Catarina et utilise les textes scholaires normatifs comme source de la recherche. Les caractéristiques trouvées dans les textes sur l'enseignement d'Arithmétique révèlent des traces de l'influence à São Paulo du matériel didactique et de la méthodologie de l'enseignement de l'Arithmétique prescrite pour une utilisation à Santa Catarina.

Mots-clé: arithmétique, groupe scolaire, législation. 


\section{Introdução}

mplantado inicialmente em São Paulo, o modelo dos grupos escolares difundiu-se pelos demais Estados do país no final do século 19. São Paulo seguiu fornecendo, inclusive, modelo e mão-de-obra especializada para a instalação de sistemas similares em outros Estados. Particularmente para Santa Catarina, a vinda do professor paulista Orestes Guimarães foi determinante para a implantação deste modelo dos grupos escolares, associado a um conjunto de outras normativas que organizou o sistema escolar, incluindo a formação dos professores.

Desta história mais ampliada, este texto apresenta resultados de pesquisa relativa ao tema da história da educação matemática. Procura-se analisar a trajetória da constituição dos saberes elementares matemáticos presentes no nível primário, particularmente no Estado de Santa Catarina.

Compreende-se como saberes elementares matemáticos, no período estudado, aqueles conteúdos da matemática escolar presentes para ensino no curso primário. $\mathrm{Na}$ perspectiva de elaboração de uma pesquisa em perspectiva histórico-comparativa, procura-se elaborar um texto que avança na direção da produção de um conhecimento glocal ${ }^{1}$, entendido como articulação das produções locais em perspectiva ampliada.

Para a elaboração desta pesquisa considerou-se a positividade da escola, isto é, a perspectiva orientadora que se afasta de posicionamentos de que a escola é um lugar de repetição, de pura reprodução e lugar de atraso relativamente às demandas sociais. De forma dinâmica, de construção e elaboração permanente, a escola é vista como um lugar de uma cultura particular denominada, na perspectiva de Julia (2001), de cultura escolar. Seguindo essa trajetória, esta pesquisa tomou o intramuros da ambiência educativa e privilegiou, como fonte de pesquisa, documentos normativos relativos à implantação da reforma da instrução pública no decorrer do início do século 20 no Estado de Santa Catarina.

\section{A constituição dos grupos escolares em São Paulo}

O cenário do Brasil Imperial da metade do século 19, formado, essencialmente, pelo latifúndio escravista dominado pela elite rural, com o passar dos anos, foi minado, notadamente a partir de 1870, quando esteve presente a evolução dos meios de transporte, o surgimento da rede ferroviária e a navegação a vapor. No Oeste paulista as fazendas de café ganharam o status de empresa, com os proprietários mecanizando a produção. Nas regiões onde antes se produzia açúcar com seus velhos engenhos estes foram, aos poucos, sendo substituídos por usinas mais modernas. $O$ crescimento populacional, a crise do sistema escravista e a lenta substituição do trabalho servil pelo trabalho assalariado foram elementos que contribuíram para mudanças.

As mudanças políticas chegaram com a queda da Monarquia e a instalação do regime republicano em 1889. Durante a Primeira República, o projeto educacional das classes dominantes apresentava-se como um projeto político-ideológico e um projeto de realizações práticas. Os intelectuais, educadores e políticos liberais difundiram,

\footnotetext{
${ }^{1} \mathrm{O}$ termo remete aos escritos de Roger Chartier: "A união indissociável do global e do local tem levado alguns a proporem a noção de glocal, que designa com correção e elegância, os processos pelos quais são apropriadas as referências compartilhadas, os modelos impostos, os textos e os bens que circulam em escala planetária, para cobrar sentido em um tempo e em lugar concretos" (2010, p. 81). 
propagandearam e instituíram suas concepções de educação popular por meio da imprensa e do poder legislativo, principais canais de expressão político-social. Consolidaram, por meio de seus discursos, um imaginário segundo o qual a educação escolar era relevante para a vida política e social. Dessa forma, esta elite reforçou o poder da educação como fator de promoção e igualdade social e a fixação dos perfis quanto à função e as possibilidades sociais de um homem educado, detentor da razão, enquanto que o homem analfabeto era considerado um ignorante (Souza, 1998a).

A confiança na instrução, como elemento conformador dos indivíduos, era o pressuposto da crença do poder da educação. Criadora do homem moral, a educação foi associada à cidadania e, articulada com a valorização da ciência e com os rudimentos de uma cultura letrada, apresentava-se como interpretação conciliadora capaz de explicar os motivos do atraso da sociedade brasileira e apontar a solução para o mesmo (Souza, 1998b).

O Estado de São Paulo, por meio do decreto n. 27, de 12 de março de 1890, inaugurou a marca republicana no âmbito das políticas públicas: os múltiplos aspectos do sistema de ensino - estrutura administrativa, organização curricular, legislação específica e minuciosa - são produzidos, impulsionados e controlados pela ação legislativa do governo. A criação da escola-modelo em prédio anexo à Escola Normal concretizou a crença da imprescindibilidade da formação dos professores para a renovação da escola pública, representada com a adoção de novos processos de ensino, em especial o método intuitivo. A existência de um locus para a formação prática dos normalistas, objetivando a aprendizagem dos modernos métodos, servindo de campo de experimentação, consolidar-se-ia como centro de irradiação da escola renovada (Costa, 2010).

Caetano de Campos, diretor da Escola Normal, procurou profissionais com domínio dos novos métodos. Por indicação do professor Lane, diretor da Escola Americana, contratou as professoras Maria Guilhermina Loureiro de Andrade e Márcia Priscilla Browne, ambas formadas nos Estados Unidos e com muita afinidade ao método intuitivo. Cada uma delas dirigiu uma das seções da escola-modelo. Após o primeiro ano de funcionamento da escola-modelo, a diretora Maria Guilhermina Loureiro de Andrade pediu rescisão de contrato, permanecendo Márcia Browne na direção das duas seções ${ }^{2}$. As articulações de Caetano de Campos na escolha destas professoras representam a crença no método e consagra a influência americana nesse primeiro período de reforma da instrução pública no Estado de São Paulo.

A partir da implantação da escola-modelo, foram necessários cinco anos para que fosse completado o número de classes e séries do ensino preliminar ${ }^{3}$. Neste período foram gestados, dentre outros aspectos, a normatização da disciplina escolar, a prática do método intuitivo, a distribuição das matérias e do tempo escolar.

A Constituição de 1891 institucionalizou a descentralização e segmentou em dois blocos a administração da educação: o federal e o estadual. O ensino superior e secundário ficou a cargo da administração federal, enquanto que o ensino primário,

\footnotetext{
2 Anos mais tarde a professora Maria Guilhermina foi convidada para dirigir um grupo escolar em Belo Horizonte, na época da implantação dessa modalidade de escola em Minas Gerais. Ver Faria Filho (1996), Souza (1998a).

${ }^{3} \mathrm{O}$ ensino primário era composto por dois cursos: o preliminar e o complementar. Hist. Educ. [Online] Porto Alegre v. 18 n. 44 Set./dez. 2014 p. $27-43$
} 
profissionalizante e de formação dos professores ficou a cargo da administração estadual (Werle, 2005).

O Distrito Federal e o Estado de São Paulo foram as primeiras unidades federativas a implantar as reformas que resultaram em um sistema público de ensino primário gratuito, sendo que tais iniciativa serviram, posteriormente, de modelos aos demais Estados, dado que o governo central não formulou qualquer proposta a este respeito.

\section{Orestes Guimarães: um paulista em terras catarinenses}

O então governador de Santa Catarina, Gustavo Richard (1906-1910), considerado um entusiasta republicano, alinhou-se nas ações que estavam em pleno desenvolvimento nos Estados de São Paulo, Minas Gerais e Rio de Janeiro.

Por meio da lei n. 765, de 17 de setembro de 1907, garantiu ao Estado de Santa Catarina a possiblidade de "commissionar um professor público que exerça o magistério há dous annos, pelo menos, para em qualquer dos Estados da República, onde a instrucção lhe pareça melhor orientada" (Santa Catarina, 1907).

A influência paulista se materializou com a vinda do professor paulista Orestes Guimarães, inicialmente para dirigir o Colégio Municipal de Joinville (1907-1909). Contando com o apoio do governo regional e sua habilidade política, Orestes recebeu a simpatia do sucessor no comando do Estado, tornando-se inspetor-geral da Instrução Pública, em 1910, no governo de Vidal Ramos (1910-1914).

A reforma da instrução pública, ocorrida em Santa Catarina a partir da lei n. 846/1910, é tida como a mais importante reforma do ensino deste Estado, considerandose aquelas empreendidas ao longo do século. Esta reforma trouxe para a educação catarinense grandes mudanças, seja como reorganização escolar ou como concepção pedagógica de escola graduada, baseadas nos ideais liberais e positivistas do método intuitivo ${ }^{4}$ (Nóbrega, 2003).

A participação singular de Orestes Guimarães na reforma catarinense possibilitou a construção de uma história em perspectiva glocal, em que as questões históricas locais estão associadas às questões históricas globais, conforme aponta Roger Chartier (2010), para quem a noção de glocal designa "os processos pelos quais são apropriadas as referências partilhadas, os modelos impostos, os textos e os bens que circulam mundialmente, para fazer sentido em um tempo e em um lugar diferente" (p. 57).

Orestes Guimarães é a figura que permite esta reflexão das referências partilhadas entre a reforma estabelecida em São Paulo e a reforma da instrução pública implantada em Santa Catarina ${ }^{5}$.

\section{Reformando o ensino público: lei n. 846, de 11 de outubro de 1910}

Em Santa Catarina a lei n. 846, de 11 de outubro de 1910, autorizou a alteração do ensino público e deu início à reforma com o estabelecimento da rede de ensino pelas escolas ambulantes, escolas isoladas, grupos escolares e escola normal.

\footnotetext{
4 "O método intuitivo surgido na Alemanha no final do século XVIII, pela iniciativa de Basedow, Campe e sobretudo de Pestalozzi [...] consistia na valorização da intuição como fundamento de todo conhecimento, isto é, a compreensão de que a aquisição dos conhecimentos decorria dos sentidos e da observação" (Souza, 1998a, p. 26).

${ }^{5}$ Ver Silveira (2013). Hist. Educ. [Online] Porto Alegre v. 18 n. 44 Set./dez. 2014 p. $27-43$
} 
Ao implantar os grupos escolares entre as escolas públicas estaduais, os reformadores catarinenses determinaram um modelo muito claro para a educação primária. De acordo com Souza (1998a, p. 20), os grupos escolares eram "um modelo de organização do ensino elementar mais racionalizado e padronizado com vistas a atender um grande número de crianças, portanto, uma escola adequada à escolarização em massa e às necessidades da universalização da educação popular".

Os grupos escolares não foram os únicos modelos de escolas estabelecidos na reforma. As escolas isoladas, herança das escolas de primeiras letras ${ }^{6}$, foram mantidas na reforma, sendo que nas sedes dos municípios eram chamadas de preliminares, nas sedes dos distritos de intermédias e nos bairros de provisórias. Eram nelas que se formavam a maioria das crianças.

O artigo 51 do decreto n. 585, de 19 de abril de 1911, que reorganizou a instrução pública primária do Estado de Santa Catarina, prescreveu que as escolas isoladas deveriam ser "criadas de preferência nos perímetros urbanos e suburbanos dos municípios que não tiverem grupo escolar" ou "nos perímetros suburbanos dos municípios que tiverem grupo escolar, localizados, porém, de acordo com a disseminação da população". Segundo Teive e Dallabrida (2011), o funcionamento das escolas isoladas era bastante precário, mas foi por meio delas que a maioria da população teve acesso à escola primária.

Entretanto, os grupos escolares, que formavam uma minoria, "congregavam o que, em termos de ensino, havia de melhor à época [...] e deveriam dispor - e parece que dispunham de fato - de um conjunto de recursos didático-pedagógicos, que se distinguiam daqueles disponibilizados ao conjunto mais alargado da população que frequentava as escolas públicas" (Silva, 2006, p. 345). Os grupos escolares se configuram como uma escola para a elite catarinense.

A estrutura física e pedagógica dos grupos escolares possuíam características próprias que influenciavam a formação do professor da escola normal, sendo que tudo estava organizado em função do método intuitivo e do ensino simultâneo:

Os grupos escolares eram amplas construções [...] possuíam salas internas espaçosas - para até 45 alunos, arejadas por amplas janelas, de modo que a claridade incidisse adequadamente na carteira do aluno. [...] possuíam ainda salas de depósito, galpões e o gabinete do diretor. Um prédio planejado para atender aos fins e às práticas pedagógicas pretendidas com a reforma. [...] Esta reorganização da escola primária pressupunha a uniformização e seriação dos conteúdos, distribuídos racionalmente no tempo de curso, e uma homogeneização dos grupos de alunos de modo que em cada classe todos estivessem dentro de uma mesma faixa etária e de um mesmo grau de desenvolvimento escolar havendo separação entre sexos, sujeitos ao ensino simultâneo. (Nóbrega, 2003, p. 255)

Dentro do conjunto proposto pela reforma, a Escola Normal Catharinense deveria formar o professorado na pedagogia moderna, "pois seriam eles responsáveis diretos pela instauração, nas novas formas escolares recém-inauguradas, da nova cultura escolar,

\footnotetext{
${ }^{6}$ Em 1827 uma Lei Imperial instituiu as Escolas de Primeiras Letras, conhecidas como escolas para aprender a ler, escrever e contar (Brasil, 1827). 
alicerçada nos pressupostos do novo método de ensino" (Teive, 2007, p. 116). No entanto, devido ao fato do Estado possuir apenas uma escola normal, que se localizava na capital, os reformadores catarinenses optaram por exigir a formação na escola normal apenas para os professores que iriam lecionar nos grupos escolares. Para as escolas isoladas, que eram a grande maioria, a formação exigida para o professor era ao nível complementar ${ }^{7}$.

Em São Paulo o curso complementar também tinha "o objetivo adicional que Ihes foi dado de preparar professores para as escolas", no entanto, diferentemente de Santa Catarina, os habilitados nesta escola acessariam o magistério "mediante o acréscimo de um ano de prática de ensino nas escolas modelos" (Tanuri, 2000, p. 69).

De certa forma, a diferenciação na formação dos professores e na estrutura físicopedagógica das escolas, fez com que a escola normal se tornasse "uma escola de excelência, [que] formava professores para os grupos escolares - uma escola primária também de excelência" (Teive; Dallabrida, 2011, p. 70).

Quanto ao provimento destas escolas, a legislação previa que os grupos escolares, cujo curso primário era realizado em quatro anos, fossem regidos por normalistas. As escolas preliminares, cujo curso primário era realizado em três anos, deviam ser regidas também por normalistas. No entanto, as escolas intermédias, cujo curso primário era também de três anos de duração, deviam ser regidas por professores vitalícios ou efetivos - não normalistas. Finalmente, as escolas provisórias, cujo curso primário tinha três anos de duração, deviam ser regidas por professores nomeados (Santa Catarina, 1911b).

Segundo Hoeller (2009, p. 65), "os professores formados pela Escola Normal poderiam estar mais cotados à docência nos grupos escolares e, em segundo plano, os complementaristas".

\section{A Matemática na formação dos professores: a escola normal}

O decreto n. 586, de 22 de abril de 1911, instituiu o programa e horário da escola normal. A sexta cadeira é constituída da Aritmética, Álgebra e Geometria Plana. Como se observa no quadro abaixo, a Aritmética estava presente nos três anos de formação do futuro professor na escola normal. O quadro de horário geral publicado no anexo a este decreto indica que a Aritmética era ministrada em três aulas por semana no $1^{\circ}, 2^{\circ}$ ano e $3^{\circ}$ ano. As aulas deviam ser de 50 minutos no $1^{\circ}$ e $2^{\circ}$ ano e de 40 minutos no $3^{\circ}$ ano. A Álgebra estava no $2^{\circ}$ ano, com três aulas por semana de 50 minutos, e a Geometria no $3^{\circ}$ ano, com três aulas semanais de 40 minutos. Ainda segundo o quadro de horário geral, o professor Fernando Machado era o responsável por todas estas aulas.

Outro decreto anterior, n. 572, de 25 de fevereiro de 1911, apresenta considerações acerca do exame de admissão para ingresso na escola normal, ou seja, determina aquilo que era considerado essencial para o acompanhamento do curso. Da parte de Matemática, encontram-se:

\footnotetext{
${ }^{7}$ O Curso Complementar deveria funcionar nos prédios dos grupos escolares e tinha por objetivo completar o ensino iniciado nestas escolas, assim como preparar candidatos para o magistério, pois o curso possuía a duração de três anos que correspondiam ao programa dos dois primeiros anos da escola normal. A conclusão do curso habilitaria o candidato a professor a se matricular no último ano da Escola Normal (Santa Catarina, 1911b).
} 
Artigo $2^{\circ}$. - O exame de admissão na Escola Normal versará sobre preliminares das matérias do primeiro anno normal, a saber: [...] Arithmetica - Resolver quatro problemas fáceis nos quaes entrem simultaneamente as operações sobre os inteiros, fracções ordinárias e decimaes. Conhecer praticamente os caracteres da divisibilidade. Achar praticamente o maximo commum divisor e o minimo multiplo commum, conforme os diversos processos. Decompor um numero em seus factores primos. Fracções - Reduzir fracções ao mesmo denominador. Simplificalas e extrahir os inteiros. Tudo praticamente. [...] Desenho - Construir conforme as regras - angulos, triangulos, polyonos em geraes. Combinações de formas geometricas ao redor de um centro. Estrellas e suas inscripções. (Santa Catarina, 1911a)

Quadro 1

Programa e horário da Escola Normal do Estado de Santa Catharina - 1911.

\section{Sexta cadeira \\ (Arithmética, Algebra e Geometria plana) \\ Arithmetica \\ $1^{\circ}$ Anno}

$1^{\circ}$ - Quantidade, numero e numeração. Signaes.

$2^{\circ}$ - Estudo das seis operações sobre números inteiros.

$3^{\circ}$ - Divisibilidade. Principios fundamentaes. Caractéres da divisibilidade. Numeros múltiplos, submúltiplos e primos.

$4^{\circ}$ - Fracções ordinárias. Principios e propriedade. Simplificação. Reducção ao mesmo denominador. Operações. Fracções mixtas e fracção de fracção.

$5^{\circ}$ - Fracções continuas. Ligieras noções sobre a origem e utilidade das fracções continuas.

$6^{\circ}$ - Fracções decimaes. Principios e propriedades. Operações. Conversão de uma fracção decimal em ordinaria.

$7^{\circ}$ - Dizimas periódicas. Definições. Conversão de uma fracção ordinaria em decimal. Dizimas simples e compostas. Caráteres para conhecer as especies de dizimas (geratrizes).

$8^{\circ}$ - Numeros complexos. Transformação dos numeros complexos em fracção ordinaria e viceversa. Operações.

Nota: sobre todos os pontos dados será feitos variados exercícios.

\section{$2^{\circ}$ Anno}

$1^{\circ}$ - Metrologia Systema metrológico brasileiro. Definições. Multiplos e sub múltiplos. Unidades de comprimento, superfície, volume, peso, capacidade, monetárias, angulares e de tempo (Variados exercícios). Conversão das unidades do antigo systema para o moderno e vice-versa. (Idem).

$2^{\circ}$ - Razões e proporções. Principios das equidifferenças a proporções.

$3^{\circ}$ - Regra de tres simples.

$4^{\circ}$ - Regra de juros simples.

$5^{\circ}$ - Regra de desconto por fora.

$6^{\circ}$ - Regra de sociedade simples e composta.

Problemas sobre todos os pontos. Livro adoptado - Postillas do Lente e Artihmetica de Trajano, Curso Superior.

\section{$3^{\circ}$ Anno}

$1^{\circ}$ - Primeiro semestre, recapitulação dos pontos de arithmetica do primeiro anno, a juízo do lente e no segundo semestre, idem dos pontos do segundo anno. 


\section{Algebra \\ $2^{\circ}$ Anno}

$1^{\circ}$ - Signaes de quantidade, operação e relação. Expressões algébricas.

$2^{\circ}$ - Termos semelhantes e sua redução.

$3^{\circ}$ - Monomios, binômios e polynomios. Gráo. Polynomios ordenados e completos e incompletos.

$4^{\circ}$ - Emprego dos signaes algébricos como meio de simplificação e das letras como meio da generalização.

$5^{\circ}$ - Estudo elementar das quatro operações.

$6^{\circ}$ - Equações simultâneas. Methodos de eliminação.

$7^{\circ}$ - Problemas.

Livro adoptado - postilas do Lente e Algebra de Trajano.

\section{Geometria \\ $3^{\circ}$ Anno}

$1^{\circ}$ - Idéa do corpo, superficie, linha e ponto.

$2^{\circ}$ - Angulos.

$3^{\circ}$ - Linhas perpendiculares, obliquas e parallelas.

$4^{\circ}$ - Circumferencia e principaes linhas nella existentes.

$5^{\circ}$ - Triangulos.

$6^{\circ}$ - Quadrilateros.

$7^{\circ}$ - Polygonos em geral. Polygonos inscriptos e circumscriptos.

$8^{\circ}$ - Medida das linhas e dos ângulos.

$9^{\circ}$ - Area do triangulo, parallelogamo, rectangulo, trapézio, quadrado, circulo, polygono regular.

$10^{\circ}$ - Ligeiras noções sobre o valor do ð. Rectificações de circumferencia. Problemas.

Livro adoptado - Geometria de Timotheo e Postillas do Lente.

Fonte: SANTA CATARINA. Programma e horario da escola normal do Estado de Santa Catharina. Decreto n. 586, 22 abr. 1911. Florianópolis: Gab. Typ. D’O dia, 1911c. Disponível em: <http://repositorio.ufsc. br/xmlui/handle/123456789/99195>. Acesso em: 15 dez., 2013.

\section{A Matemática para os alunos: os grupos escolares e as escolas isoladas}

Desde a grande reforma introduzida em 1910, há programas para os grupos escolares e escolas isoladas em 1911, 1914, 1920, 1928, 1939 e 1946. O decreto n. 587, de 22 de abril de 1911, indica Aritmética, Desenho e Geometria para os quatro anos dos grupos escolares. Para as escolas isoladas, apenas a Aritmética figura nos três anos do curso. O decreto n. 796, de 2 de maio de 1914, aponta Aritmética e Desenho para os quatro anos dos grupos escolares. A Geometria Prática era introduzida no segundo ano do curso e Geometria nos terceiro e quarto ano. Para as escolas isoladas, permanece a Aritmética nos três anos do curso.

O decreto n. 1.322, de 29 de janeiro de 1920, explicita, para os grupos escolares, Aritmética e Desenho nos quatro anos de curso, embora a Geometria somente é iniciada a partir do segundo ano. Para as escolas isoladas há menção da Geometria e Desenho no segundo e terceiro ano do curso primário. Em 1928 há uma alteração nos grupos escolares com a exclusão da Geometria e Desenho no primeiro ano do curso, permanecendo o restante do curso como nos anos anteriores, isto é, com Aritmética nos quatro anos e Geometria e Desenho a partir do segundo ano de curso. No decreto n. 714, de 1939, indica-se o programa de modo geral, isto é, estão contempladas as disciplinas 
de Aritmética, Geometria e Desenho. Para 1946, para as escolas isoladas, escolas reunidas e grupos escolares passa-se a referenciar a Iniciação Matemática.

Uma vez que há um longo percurso na trajetória da Matemática no ensino primário em Santa Catarina, este texto não irá se debruçar numa análise mais pormenorizada em todo período relatado pelos documentos enumerados acima. De fato, elege-se o programa de 1914 para se relatar os vestígios presentes nesta legislação para demarcar o ideário que norteava tais ações pedagógicas neste período de implantação dos grupos escolares no Estado.

Pelo decreto n. 795, de 2 de maio de 1914, aprovou-se o regimento internos dos grupos escolares, que dispõe, minuciosamente, elementos de composição, funcionamento e detalhamento dos conteúdos a serem ensinados em cada ano e as formas de fazê-lo:

Art. 52. - O ensino de arithmetica terá em vista desenvolver o raciocinio, ministrar noções necessárias á vida pratica. As denominações e as definições, succintas, dos diversos assumptos, e que se façam necessarias, serão deduzidas dos exemplos, pelos alunos. [...]. Art. 57 Para o ensino de desenho será adoptado o methodo directo. Como preliminar estabelecer no espirito dos alunos o habito da observação, da ordem e do asseio nos trabalhos. [...] Art. 60 - É prohibido os alunos decorarem compêndios ou mesmo apontamentos fornecidos ou dictados pelos professores. (Santa Catarina, 1914a)

Segundo Silveira (2013), Orestes Guimarães anunciava acreditar nos preceitos da pedagogia moderna. Desde a reforma de 1911, ele demonstra a base do sistema escolar implantado no método intuitivo e revela acreditar que o método veio dar estrutura à reforma, determinando as características das escolas e fazendo da escola normal o estopim desta mudança. Tal discurso deixa transparecer que estava no método a garantia de sucesso, tanto da aprendizagem do aluno, quanto do desenvolvimento do país:

Sabido que a eficiência da reforma estava na mudança dos métodos e que estes só seriam melhorados com a reforma da Escola Normal e com a criação de um novo tipo de escola que se prestasse, por suas especiais condições, a acompanhar a evolução que em matéria de ensino se vai notando em todo o país, foi iniciada a reforma. (Guimarães apud Régis, 1914, p. 124)

O discurso crítico quanto à escola tradicional, empreendido por Orestes Guimarães, pode ser associado ao pensamento sobre o método intuitivo na Europa, em meados do século 19, que acusava a escola de formar

alunos com domínio insuficiente da leitura e escrita e com noções de cálculo insatisfatórias, principalmente pelo fato de alicerçar a aprendizagem exclusivamente na memória, priorizar a abstração, valorizar a repetição em detrimento da compreensão e impor conteúdos sem exame e discussão. (Valdemarin, 1998, p. 67)

Assim, o novo método trazia a proposta de combater o "caráter abstrato e pouco utilitário da instrução", investindo no "concreto, racional e ativo, denominado ensino pelo aspecto, lições de coisas ou ensino intuitivo" (Valdemarin, 1998, p. 68): 
todas as atividades propostas devem motivar o aprimoramento da observação e da inteligência consistindo em imitações das formas e objetos existentes no cotidiano da criança [...]. A superioridade do método intuitivo consiste na colocação de fatos e objetos para serem observados pelos alunos, criando situações de aprendizagem em que o conhecimento não é meramente transmitido e memorizado, mas emerge no entendimento da criança a partir dos dados inerentes ao próprio objeto. (Valdemarin, 1998, p. 70)

Desta forma, como aponta Valdemarim (1998, p. 69), o método intuitivo pode ser resumido em dois pontos: observar e trabalhar, sendo que "observar significa progredir da percepção para a ideia, do concreto para o abstrato, dos sentidos para a inteligência, dos dados para o julgamento". Com relação ao trabalhar, o método intuitivo pensava em "fazer do ensino e da educação na infância uma oportunidade para a realização de atividades concretas, similares àquelas da vida adulta".

Assim, o trabalho pedagógico esperado pelos reformadores da instrução pública catarinense para a Matemática e para as outras disciplinas estava relacionado ao trabalho prático que o aluno deveria realizar sobre os objetos, pela observação direta dos fatos. $O$ conhecimento passa pela percepção do aluno frente ao objeto e não pela transmissão do conhecimento pelo professor e memorização deste conhecimento pelo aluno.

Retomando o programa de ensino prescrito no decreto n. 796 , de 2 de maio de 1914, para os grupos escolares, encontramos, para o ensino de Arihtmetica do primeiro ano, instruções detalhadas.

Quadro 2 -

Programa dos Grupos Escolares Estado de Santa Catharina (Aritmética) - 1914.

\section{Arithmetica.}

(Primeira phase: sessões A, B e C. A ideia de numero antez da de algarismo.)

O professor muna-se de collecções de objetos iguaes, bem sensiveis á vista dos alumnos, pelas suas dimensões - lugar em que estejam colocados - e estabeleça palestras encaminhando o ensino, de modo que, apresentada uma collecção - ora de tres, ora de quatro, de seis, sete, etc., dez objetos - eles divulguem e digam quantos são, ex:

-Paulo, quantas taboinhas tenho aqui?

-Quatro taboinhas.

- (Retirando as mãos atraz das costas e apresentando a coleção augmentada).

- E agora?

- Nove taboinhas.

- E agora, Julio?

- Dez taboinhas.

(Pratiquem bem estes exercicios variando o emprego das quantidades das collecções de objetos e augmentando-as paulatinamente até 20).

\section{Os mesmos exercicios subtrahindo, ex:}

- Julio, quantas pedrinhas estão aqui?

- Ahi estão seis pedrinhas. 
- Quantas em cada mão?

- Tres em cada mão.

- Tirando tres pedrinhas de seis pedrinhas quantas ficam, José?

- Olhem, são seis, tres em cada mão; eu tiro tres, quantas ficam?

- Tres.

- E agora, quantas são?

- Oito.

- Tirando duas, Mario?

- Ficam seis pedrinhas.

- E mais quatro, Placido?

- São dez pedrinhas.

(Pratique bem estes exercicios, que o professor variará á vontade.)

Os mesmos exercicios multiplicando, ex:

Os mesmos exercicios dividindo, ex:

(...)

Nota. Em geral as crianças maiores de seis annos já entram para a escola com idéa dos cinco primeiros numeros, porém, sem a idéa das diversas combinações ou operações que podem ser realizadas com esses numeros. - Assim, é de toda conveniencia que o professor pratique, por todos os meios ao seu alcance, os exercicios acima - sommar, diminuir, multiplicar e dividir, partindo estas operações ou combinações do mais concreto para o abstracto.

Não deve ter pressa, pois, o ensino desta disciplina, por sua natureza, deve ser methodizado de modo que desenvolva sobretudo o raciocínio, suggira e cultive o espirito de deducção. É pois uma phase educativa.

(Segunda phase, Secções A, B e C). Copia e leitura do quadro de Parker. Solução completa e perfeita das 24 primeiras paginas do quadro de Parker para a secção $\mathbf{A}$; até a 16 para a secção $\mathbf{B}$ e até a 12 para a secção $\mathbf{C}$.

(O professor antes de ministrar as licções de cada pagina do quadro, deve estudar os conselhos relativos ás mesmas afim de tornar proficuas as suas aulas).

(Terceira phase, para a secção A de meado de Outubro em deante.)

Pequenos problemas relativos ás quantidades e combinações anteriormente estudadas contar, sommar, diminuir, multiplicar e dividir até 100.

Fonte: Santa Catarina, 1914b.

O quadro que segue ilustra o programa para o primeiro ano de Arithmetica para as escolas isoladas. 
Quadro 3 -

Programa das Escolas Isoladas do Estado de Santa Catharina (Aritmética) - 1914.

\section{Arithmetica}

$1^{\circ}$ anno

Programma - Contar de um até 10; de 10 até 20; de 20 até 50; de 50 até 100. (Quadro de Parker.) De 100 até 200; de 200 até 300; de 300 até 500; 600, 700, 800, 900 e 1000. Sommar, subtrahir, multiplicar e dividir, usando dos signaes,,$+- \times, \div e=$, no quadro de Parker.

Somma e subtracção. (Não é permitido o uso de compedio.)

\section{$2^{\circ}$ anno}

Programma - Ler e escrever numeros. Somma e subtracção, estudo completo. Multiplicação e divisão. Calculos mentaes. Problemas sobre a somma, sobre a subtracção e, combinadamente, sobre a somma e subtracção.

(Não é permitido o uso de compendio.)

\section{$3^{\circ}$ anno}

Programma - Multiplicação e divisão, estudo completo. Calculos mentaes rapidos sobre a somma, subtracção, multiplicação e divisão. Problemas sobre a multiplicação e divisão e sobre ambas operações conjuntamente.

Ler e escrever fracções ordinárias e decimaes. Sommar, diminuir, multiplicar e dividir fracções decimaes. Idem fracções ordinarias. Conhecimento do metro, litro, grammo, multiplos e submultiplos. (É prohibido o uso de compendio): Para o professor porém, é indicado o "Livro do Mestre" de Ramon Rocca, cujos problemas se prestam ao desenvolvimento do programma.

Fonte: Santa Catarina, 1914b.

Em ambas situações acima observa-se a graduação dos exercícios e a prescrição do Quadros de Parker, tanto para os grupos escolares, quanto para as escolas isoladas.

\section{Os quadros de Parker e Livro do mestre de Ramon Rocca: marcas paulistas em Santa Catarina}

Em São Paulo os quadros de Parker foram muito valorizados e divulgados, permitindo que Orestes Guimarães também adotasse para Santa Catarina este material. Estes quadros parecem ser o material mais divulgado e simbolizavam a modernidade através das coisas.

De acordo com Costa (2010), Francis Wayland Parker foi o criador de um sistema numérico que apresentava a Aritmética de forma intuitiva e era chamado de cartas, quadros ou mapas de Parker.

Para Valente (2011, p. 85), o nome de Parker estava relacionado ao ensino da Matemática na reforma de instrução paulista, sendo "garantia de mudança, de ruptura com o modelo considerado ultrapassado do ensino da matemática pela memorização, pelo verbalismo e pela ordenação lógica dos conteúdos a ensinar". Segundo o mesmo autor, as orientações pedagógicas advindas das ideias de Parker estavam presentes na "legislação educacional, nas revistas pedagógicas e nos livros didáticos para o ensino de matemática" (p. 84) do Estado de São Paulo: 
As Cartas de Parker constituem um conjunto de gravuras cujo fim é o de auxiliar o professor a conduzir metodicamente o ensino, sobretudo, das quatro operações fundamentais. Junto de cada gravura, há uma orientação ao professor de como deveria dirigir-se à classe de modo a fazer uso de cada uma delas e avançar no ensino de Aritmética. (Valente, 2011, p. 87)

Podemos relacionar este material com um estudo dirigido que está organizado em forma de perguntas do professor que determinam respostas dos alunos. Este diálogo se caracteriza como uma lição intuitiva:

A lição intuitiva é professada pelo mestre numa linguagem apropriada à idade dos alunos. Dada sob a forma de diálogo, ela apela à espontaneidade das crianças numa troca animada de perguntas e respostas, suscitadas de uns para os outros, provocando e dirigindo a atividade das faculdades intelectuais [...]. Sua característica distintiva, que é a característica geral específica do método, é partir da observação direta e imediata, para fazer as crianças raciocinarem na presença do fato observado. (Delon, 1913 apud Valdemarim, 1998, p. 70)

Não somente as cartas de Parker levavam a marca da influência paulista. A obra indicada, Livro do mestre, de Ramon Roca Dordal, também é vestígio desta ação engendrada e iniciada por Orestes Guimarães.

Na Europa e na América, no último quarto do século 19, o crescimento do consumo de livros didáticos está associado à consolidação dos sistemas nacionais de educação pública. O crescimento do mercado de livros escolares é parte integrante das condições de infraestrutura física e cultural necessárias para essa consolidação (Razzini, 2004).

A expansão da escola pública no Estado de São Paulo acelerou o desenvolvimento do mercado editorial e ampliou o mercado de trabalho, envolvendo professores, artistas, editores, técnicos na escrita, ilustração e produção de livros didáticos.

O modelo de ensino traduzido na invenção dos grupos escolares exigia não somente prédios e móveis específicos, mas também o uso de novos materiais didáticopedagógicos como livros, cadernos, além de mapas e cartazes. As novas delimitações dos espaços e tempos impostas pelo modelo de racionalidade organizacional e pedagógica contribuíram para afirmação do ensino simultâneo e para a uniformização e seriação de conteúdos. Tal configuração exigia uma variedade muito maior de livros e de outros materiais didáticos adaptados ao ensino graduado de todas as matérias do currículo.

A centralização e hegemonia do ensino primário paulista, a partir da Escola Normal Caetano de Campos, evidenciou um grupo de normalistas que lá se formaram e que, além de exercerem cargos-chave na hierarquia da instrução pública, se tornaram autores de livros didáticos.

Este processo é explicado mediante o entendimento das ações de controle que são exercidas no chamado circuito do livro escolar. Em São Paulo, desde o início da República, e posteriormente em Santa Catarina, o governo controlou a adoção dos livros didáticos nas escolas públicas, quer seja sob a alegação da necessidade de uniformização do ensino, quer seja porque legislava sobre programas e currículos, ou ainda por se tornar em principal comprador deste produto. 
A indicação de Ramon Roca Dordal como autor de obra didática para uso nas escolas isoladas é mais um indicativo da influência paulista na implantação dos grupos escolares em Santa Catarina.

\section{Considerações finais}

O movimento internacional para a consolidação dos sistemas nacionais de educação pública foi um importante elemento que promoveu reformas na instrução pública no Brasil. A expansão da escola pública no Estado de São Paulo, no final do século 19, marcada pelo ideário republicano, recebeu influências do ensino intuitivo, materializadas, dentre outras, nas ideias de Pestalozzi.

Muitos estudos da história da educação apontam o importante papel desempenhado por São Paulo na difusão do modelo dos grupos escolares, implantados no final do século 19 e início do século 20. Surgidos no corpo das leis de 1893, em São Paulo e no Rio de Janeiro, regulamentados e instalados a partir de 1894 no Estado de São Paulo, os grupos escolares emergiram em várias outras capitais do Brasil, bem como em Santa Catarina, a partir de 1911.

O estudo das fontes utilizadas neste estudo permitiu delinear um cenário em que a matriz pedagógica do ensino intuitivo, alicerçada pela organização graduada dos estudos seriados, caracterizou uma nova formatação para o ensino da Aritmética.

A metodologia explicitada nos textos legislativos prescreve o ensino dos números na forma oral, para depois serem estudados na sua forma escrita, isto é, com o uso dos algarismos. Tal situação caracteriza-se e identifica-se com as ideias de Pestalozzi: primeiro a ideia do número, depois o uso dos algarismos. Para além desta importante consideração, os números são estudados gradativamente: de 1 até 10; posteriormente até 20; até 50 e, dentro destes grupos, os números são estudados também como resultados das operações associadas às somas, diferenças, multiplicação e divisão, tratando-os em combinações e decomposições.

A presença do método intuitivo no ensino de Aritmética revela um novo pensamento pedagógico que contraria as disposições anteriores do ensino em que se privilegiava a memorização dos saberes. As cartas de Parker são elementos que permitem associar a influência deste movimento intuitivo com a marcha do ensino da Aritmética prescrita na legislação do Estado de Santa Catarina.

A indicação do texto didático de Roca Dordal se constitui em outro importante elemento que denota a influência paulista no ensino da Aritmética no início do século 20 em Santa Catarina.

\section{Referências}

BRASIL. Lei de 15 de outubro de 1827. Manda crear escolas de primeiras letras em todas as cidades, villas e logares mais populosos do Império. Disponível em: <http://www2. camara.gov.br/legislacao/publicacoes/doimperio>. Acesso em: 10 jun., 2014.

CLARK, Jorge Uilson. A primeira república, as escolas graduadas e o ideário do iluminismo no campo da história da educação. In: LOMBARDI, José Claudinei; SAVIANI, Dermeval; NASCIMENTO, Maria Isabel Moura (org.). Navegando pela história da educação brasileira. Campinas: Gráfica Faculdade de Educação, 2006, p. 1-7. 
CHARTIER, Roger. A história ou a leitura do tempo. Belo Horizonte: Autêntica, 2010.

COSTA, David Antonio da. A aritmética escolar no ensino primário brasileiro: 1890-1946. São Paulo: PUCSP, 2010. 278f. Tese (doutorado em Educação Matemática). Pontifícia Universidade Católica de São Paulo.

HOELLER, Solange Aparecida de Oliveira. Escolarização da infância catarinense: a normatização do ensino público primário (1910-1935). Curitiba: UFPR, 2009. $210 f$. Dissertação (mestrado em Educação). Programa de Pós-Graduação em Educação, Universidade Federal do Paraná.

JULIA, Dominique. A cultura escolar como objeto histórico. Revista Brasileira de História da Educação. Campinas, n. 1, 2001, p. 9-43.

NÓBREGA, Paulo de. Grupos escolares: modernização do ensino e poder oligárquico. In: DALLABRIDA, Norberto. Mosaico de escolas: modos de educação em Santa Catarina na primeira república. Florianópolis: Cidade Futura, 2003, p. 253-280.

RAZZINI, Marcia de Paula Gregório. A Livraria Francisco Alves e a expansão da escola pública em São Paulo. SEMINÁRIO BRASILEIRO SOBRE O LIVRO E HISTÓRIA EDITORIAL, 1, 2004, Rio de Janeiro. Anais ... Rio de Janeiro: Casa de Rui Barbosa, 2004.

REGIS, Gustavo Lebon. Relatório apresentado ao Exmo. Sr. Cel. Vidal José de Oliveira Ramos. Maio de 1914. Florianópolis.

SANTA CATARINA. Lei n. 765, 17 set., 1907. Florianópolis, 1907. Acervo da Apesc.

SANTA CATARINA. Decreto n. 572, 25 fev., 1911. Florianópolis, 1911a. Acervo da Apesc.

SANTA CATARINA. Regulamento da escola normal catarinense. Decreto n. 593, 30 maio 1911. Florianópolis, 1911b. Acervo da Apesc.

SANTA CATARINA. Programma e horario da escola normal do Estado de Santa Catharina. Decreto n. 586, 22 abr. 1911. Florianópolis: Gab. Typ. D'O dia, 1911c. Disponível em: <http://repositorio.ufsc.br/xmlui/handle/123456789/99195>. Acesso em: 15 dez., 2013.

SANTA CATARINA. Regulamento para instrução pública. Decreto n. 585, 19 abr., 1911.

Gab. Typ. D'<O dia>. Florianópolis, 1911d. Acervo da Apesc.

SANTA CATARINA. Regimento Interno dos grupos escolares do Estado de Santa Catarina. Decreto n. 795, 2 maio 1914. Joinville: Typografia Boehm, 1914a. Acervo da Apesc.

SANTA CATARINA. Programa dos grupos escolares e das escolas isoladas do Estado de Santa Catarina. Decreto n. 796, 2 maio 1914. Joinville: Typ. Boehm, 1914b. Acervo da Apesc.

SILVA, Vera Lucia Gaspar da. Vitrines da república: os grupos escolares em Santa Catarina (1889-1930). In: VIDAL, Diana Gonçalves (org.). Grupos escolares: cultura escolar primária e escolarização da infância no Brasil (1893-1971). São Paulo: Mercado de Letras, 2006, p. 341-376.

SILVEIRA, Rosangela Kirst. Orientações da reforma Orestes Guimarães na Escola Normal Catharinense. Florianópolis: UFSC, 2013. 140f. Dissertação (mestrado em Educação Científica e Tecnológica). Universidade Federal de Santa Catarina.

SOUZA, Rosa Fatima de. Templos de civilização: a implantação da escola primária graduada no Estado de São Paulo: 1889-1910. São Paulo: Unesp, 1998a. 
SOUZA, Rosa Fatima de. Espaço da educação e da civilização: origens dos grupos escolares no Brasil. In: SOUZA, Rosa Fátima de; VALDEMARIN, Vera Tereza; ALMEIDA, Jane Soares de. O legado educacional do século 19. Araraquara: Unesp, 1998b, p. 11-47.

TANURI, Leonor Maria. História da formação de professores. Revista Brasileira de Educação, São Paulo, n. 14, 2000, p. 61-88.

TEIVE, Gladys Mary Ghizoni. O professor paulista Orestes Guimarães e a modernização da instrução pública catarinense (1911-1918). Cadernos de História da Educação. UFU, n. 6, 2007, p. 107-120.

TEIVE, Gladys Mary Ghizoni; DALLABRIDA, Norberto. A escola da república: os grupos escolares e a modernização do ensino primário em Santa Catarina (1911-1918). Campinas: Mercado de Letras, 2011.

VALDEMARIN, Vera Teresa. O método intuitivo: os sentidos como janelas e portas que se abrem para um mundo interpretado. In: SOUZA, Rosa Fátima de; VALDEMARIN, Vera Teresa; ALMEIDA, Jane Soares de. O legado educacional do século 19. Araraquara: Unesp, 1998, p. 63-105.

VALENTE, Wagner Rodrigues. A matemática na formação do professor do ensino primário: São Paulo 1875-1930. São Paulo: Annablume; Fapesp, 2011.

WERLE, Flávia Obino Corrêa. O nacional e o local: ingerência e permeabilidade na educação brasileira. Bragança Paulista: USF, 2005.

DAVID ANTONIO DA COSTA é doutor em Educação Matemática pela Pontifícia Universidade Católica de São Paulo e professor no Centro de Ciências da Educação e no Programa de Pós-Graduação em Educação Científica e Tecnológica da Universidade Federal de Santa Catarina.

Endereço: Rua Douglas Seabra Levier, 163 - Bloco B/208 - 88040-410 Florianópolis - SC - Brasil.

E-mail: david.costa@ufsc.br.

Recebido em 8 de maio de 2014.

Aceito em 15 de julho de 2014. 